
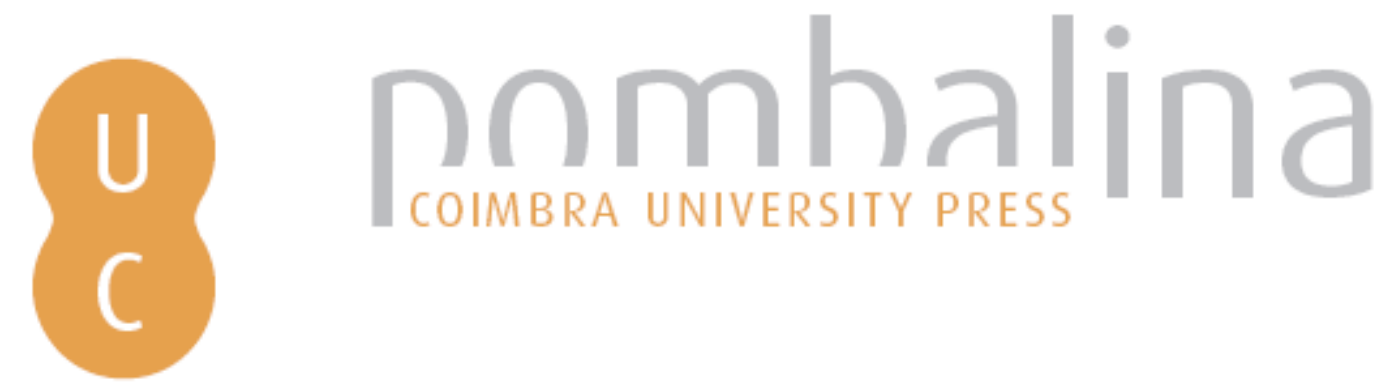

\title{
Del diálogo al texto dramático: una adaptación brasileña de los Diálogos de los muertos de Luciano de Samosata
}
Autor(es):
Fernández Robbio, Matías Sebastián
Publicado por: Centro de Estudos Clássicos e Humanísticos da Universidade de URL persistente:
Coimbra; Imprensa da Universidade de Coimbra
DOI: DOI:http://dx.doi.org/10.14195/978-989-721-038-9_22
Accessed : $\quad$ 26-Apr-2023 04:06:28

A navegação consulta e descarregamento dos títulos inseridos nas Bibliotecas Digitais UC Digitalis, UC Pombalina e UC Impactum, pressupõem a aceitação plena e sem reservas dos Termos e Condições de Uso destas Bibliotecas Digitais, disponíveis em https://digitalis.uc.pt/pt-pt/termos.

Conforme exposto nos referidos Termos e Condições de Uso, o descarregamento de títulos de acesso restrito requer uma licença válida de autorização devendo o utilizador aceder ao(s) documento(s) a partir de um endereço de IP da instituição detentora da supramencionada licença.

Ao utilizador é apenas permitido o descarregamento para uso pessoal, pelo que o emprego do(s) título(s) descarregado(s) para outro fim, designadamente comercial, carece de autorização do respetivo autor ou editor da obra.

Na medida em que todas as obras da UC Digitalis se encontram protegidas pelo Código do Direito de Autor e Direitos Conexos e demais legislação aplicável, toda a cópia, parcial ou total, deste documento, nos casos em que é legalmente admitida, deverá conter ou fazer-se acompanhar por este aviso.

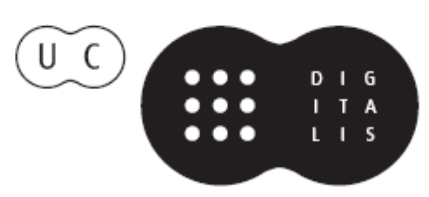




\section{De ayer a hoy}

\section{Influencias clásicas en la literatura}

\section{Aurora López, Andrés Pociña, Maria de Fátima Silva (coords.)}




\title{
Del diálogo al TEXTO DRAMÁtico: \\ UNA ADAPTACIÓN BRASILEÑa DE LOS DIÁLOGOS DE LOS MUERTOS De Luciano de Samosata
}

\author{
Matías Sebastián Fernández Robbio \\ Universidad Nacional de Cuyo
}

\begin{abstract}
Los Diálogos de los muertos son un conjunto de treinta diálogos escritos por Luciano de Samosata. Si bien primero se los consideró independientes entre sí, luego se dio paso a una comprensión unitaria de los mismos que posibilitó nuevas lecturas. La obra fue adaptada para su escenificación en 1990 por el Grupo Giz-en-Scène (Araraquara, Brasil), y, en 1996, María Celeste Consolin Dezotti publicó una traducción integral de los diálogos, que complementaría en 2003 con la publicación de su versión teatral. Analizamos aquí esta adaptación con el fin de descubrir el paso del diálogo literario al dramático, la reestructuración de la obra, y sus acotaciones escénicas y escenográficas.
\end{abstract}

\section{Transmisión de los diálogos}

Luciano de Samosata, escritor griego y ciudadano romano aunque de origen sirio, es uno de los principales representantes de la literatura griega escrita durante el Imperio Romano en el siglo II d.C. Entre sus escritos se encuentran prolaliái, diálogos, narraciones ficticias e incluso una tragedia y varios epigramas. Su obra no sólo refleja la originalidad del samosatense, sino que además evidencia su conciencia del acto mismo de creación literaria. Entre sus diálogos, se encuentra un conjunto de treinta diálogos breves que presentan pequeñas escenas dramáticas de corte menipeo situadas en el Hades, los Diálogos de los muertos.

Durante siglos, los filólogos y la crítica literaria consideraron que estos diálogos sólo constituían una unidad por su temática. El motivo de la lectura individual de los mismos se encontraba en la transmisión de los textos mismos. Dejando de lado algunos manuscritos mixtos e interpolados, los manuscritos principales de la obra de Luciano han sido agrupados en las familias $\beta$ y $\gamma$. El manuscrito B, perteneciente a la primera familia, fue el utilizado por Jacobitz al preparar la edición de la obra luciánica para Teubner. En este manuscrito, los Diálogos de los muertos aparecen en un orden que no permite leerlos como una unidad coherente sino como pequeños cuadros individuales, al modo en que luego los interpretaron Bompaire, Jones, Alsina o Baldwin (Gonzàlez Julià, 2009: 2). Sin embargo, cuando MacLeod editó estos diálogos para Oxford en 1987, siguió el orden dispuesto por el manuscrito $\Gamma$ (Vaticanus Graecus 90) de 
la familia $\gamma$, y dio paso a una nueva forma de comprenderlos que reconocía en ellos una cierta unidad narrativa.

Entre las relecturas más modernas, es necesario mencionar la de Lluís Gonzàlez Julià, quien ha propuesto considerar el conjunto de los diálogos como una "novela escénica", apuntando que:

"los Diálogos de los muertos contienen suficientes evidencias internas para que consideremos que fueron concebidos y presentados en público por Luciano -no sabemos si en audiciones o en forma de libro- como una obra unitaria y cerrada, donde las distintas piezas que la forman están interrelacionadas las unas con las otras, de manera que cada diálogo se une al anterior y al siguiente por un hilo narrativo común y por referencias metatextuales que enlazan las conversaciones. Luciano dibuja, de este modo, un viaje por el Hades en una historia completa de principio a fin, donde cada diálogo tiene su lugar." (2009: 17)

Según este mismo autor, siguiendo la numeración de MacLeod, el orden correcto de estos diálogos sería: 1, 2, 4, 5, 6, 3, 7, 8, 9, 10, 11, 12, 13, 14, 15, 16, $17,18,19,21,22,23,26,27,28,29,30$. Como se puede ver, no habría lugar para los diálogos 20, 24 y 25, que, según él, estarían interpolados.

\section{Pastiche y plasticidad en los Diálogos de los muertos}

Luciano, creador literario consciente, recurrió en sus obras a los más variados recursos y temas de la tradición literaria. Su originalidad lo llevó incluso a desafiar la distinción entre géneros literarios, hecho por el cual fue satíricamente llevado a juicio por la Retórica y el Diálogo en su propio Bis Accusatus. Al respecto, afirman Mestre y Gómez:

"Si algo caracteriza a Luciano es su carácter inclasificable. Como adalid de una cultura auténticamente individual, aparece siempre al margen de cualquier tipo de compromiso, repudió a Retórica y contaminó a Diálogo de comedia." (2001: 122)

Esta marginalidad de su obra justifica que sus diálogos sean clasificados propiamente como "diálogos luciánicos", entendidos como "una combinación de recursos de la comedia antigua y del diálogo platónico" (Cabrero, 2007: 222). La armonía entre estos dos elementos podría estar dada de diversas formas. Cabrero considera que Platón aportaría la forma, y Aristófanes, la intencionalidad satírica (ídem). De un modo parecido, Mestre y Gómez coinciden en que el diálogo es una forma pero señalan que "lo cómico" no es una intencionalidad sino un contenido que se define por oposición a "lo trágico" (2001: 113). En cambio, Wiater sostiene que la comedia no es un contenido sino una forma representacional que por su vivacidad y su inmediatez permite 
alcanzar el objetivo del diálogo filosófico, enseñarles a los lectores nuevos modos de ver y comprender el mundo (Wiater, 2009: 15). Este autor agrega que, si bien los diálogos luciánicos se parecen a la comedia en su contenido, lo que más tienen en común es lo formal: el uso de nombres cómicos, la presentación de personajes de todas las clases sociales que interactúan entre sí, la representación de acciones elevadas y cotidianas, y la utilización de vocabulario de todos los registros (16). Estos recursos, combinados con el diálogo, la diégesis in medias res y los deícticos, constituyen lo que Wiater ha propuesto llamar la "cualidad mimética" de los diálogos de Luciano, que transforman a los lectores en espectadores en la medida en que el texto contribuye a crear un escenario invisible en sus mentes. (17)

Lanaud, por su parte, propone una interpretación similar de estos textos híbridos al señalar que, en ellos, Luciano propone una puesta en escena del Hades radicalmente teatral que transforma a su obra en una "comedia infernal" (Lanaud, 2010: 23).

El pastiche utilizado como procedimiento de creación literaria a partir del diálogo platónico y la comedia aristofánica, entonces, se vuelve al mismo tiempo la causa principal de la plasticidad de estos diálogos, que ha posibilitado su adaptación teatral.

\section{E1 Grupo Giz-en-Scène y su recepción de los diálogos}

El Grupo Giz-en-Scène de lectura dramatizada de textos clásicos es un elenco brasileño que fue formado en 1987 en Araraquara (São Paulo, Brasil). Desde sus inicios ha estado integrado por profesores y alumnos de griego y latín de la Faculdade de Ciências e Letras de la Universidade Estadual Paulista Júlio de Mesquita Filho y un profesor de sánscrito de la Universidade de São Paulo. Los intérpretes y adaptadores de las obras, si bien son actores aficionados, son académicos que trabajan en el campo de los estudios clásicos.

Su relación con los Diálogos de los muertos fue mediada por la actuación profesional de Maria Celeste Consolin Dezotti, profesora de lengua y literatura griega en la FCLAR-UNESP. El elenco puso estos diálogos en escena en 1990. Entre los años 1990 y 1991, Consolin Dezotti dirigió cuatro proyectos de iniciación científica de alumnos becarios que estudiaron tres obras de Luciano: Diálogos de los muertos, Caronte e Icaromenipo. Luego, en 1996, publicó una traducción de estos diálogos y, finalmente, en 2003, salió a luz su adaptación dramática del texto, basada en su traducción. Si esta adaptación fue publicada en 2003 basándose en una traducción de 1996, cabría preguntarse qué texto sirvió de guión al elenco en 1990 y si existe alguna relación entre ese texto desconocido y la adaptación que finalmente se publicó. 


\section{Adaptación del texto original}

Los Diálogos de los muertos de Luciano, como se comentó, son un conjunto de treinta diálogos situados en el Hades, el mundo de los muertos griego regido por el dios homónimo y su esposa Perséfone, o Plutón y Proserpina en la tradición latina. Según el mito, a esta región sombría conduce Hermes, el psychopompos, a las almas de los muertos, que deben atravesar un río para ingresar al Hades conducidos en una embarcación por Caronte, personaje mitológico que cobra un óbolo por la travesía. Aquí se dan encuentro los más variados personajes (dioses, héroes, reyes, filósofos, atletas, ricos y cazadores de testamentos) igualados por la muerte y transformados en simples esqueletos y calaveras.

El texto dramático está formado por dos partes y un epílogo. La distinción de dos partes obedece a la necesidad de marcar dos momentos diferentes en la historia. La primera parte se divide en tres escenas desarrolladas junto al barco de Caronte antes de la muerte de Menipo, un filósofo cínico. La segunda parte arranca justamente después de que éste se suicidara y llegara junto a la barca de Caronte. Durante la primera escena de esta parte, los personajes embarcan en la nave del barquero y son conducidos hacia el otro lado del río. Apenas descienden, Hermes les indica a los muertos el camino que los llevará hasta el tribunal de los muertos, representado aquí únicamente por Minos. Desde ese momento, las escenas van situándose en zonas cada vez más profundas del Hades hasta llegar, en las escenas 7 y 8, a los aposentos reales de Plutón y Perséfone. Finalmente, el epílogo es un diálogo entre Hermes y Caronte, en el que este último indica su deseo de conocer el mundo de los vivos, anticipando así quizás una futura o posible puesta en escena de Caronte, otra obra de Luciano.

Las acotaciones dramáticas incluidas son escasas. En general, acompañan este movimiento desde el río hacia el interior del Hades señalando grupos de personajes que se encuentran a lo largo del recorrido y poco a poco aparecen en primer plano.

De principio a fin, la narración avanza con una construcción abierta (García Barrientos, 2003: 77) a medida que se profundiza en el Hades. No hay una acción unitaria que dé sentido a la obra ni hay un único personaje que actúe como protagonista de la misma, a pesar de que se destaquen las figuras de Diógenes en la primera parte y Menipo en la segunda. Al contrario, priman constantemente la variedad y la expansión de la historia. Por lo tanto, la adaptación propuesta puede ser considerada un drama de ambiente, en el que se suceden escenas y personajes que contribuyen a formar una imagen del mundo de los muertos.

La adaptación de los textos implicó una selección y una reordenación de los diálogos para construir una historia con una cierta coherencia entre 
los personajes que entran y salen de escena y los espacios en los que se encuentran. Por un lado, fueron descartados los diálogos 4, 8, 10, 11, 12, $16,22,23,25$ y 30 . Por el otro, los diálogos escogidos fueron reordenados libremente en las diferentes partes y escenas sin respetar los órdenes propuestos por ninguna de las ediciones del texto original griego. E1 siguiente cuadro sistematiza la relación entre las secciones de la comedia y los diálogos adaptados en ellas:

\begin{tabular}{|l|l|l|}
\hline Secciones & Diálogos adaptados \\
\hline \multirow{4}{*}{ Parte I } & Escena 1 & $14,26,13,29$ \\
\cline { 2 - 3 } & Escena 2 & $17,18,19,15$ \\
\cline { 2 - 3 } & Escena 3 & 21,1 \\
\hline \multirow{5}{*}{ Parte II } & Escena 1 & 20 \\
\cline { 2 - 3 } & Escena 2 & 2,5 \\
\cline { 2 - 3 } & Escena 3 & 9 \\
\cline { 2 - 3 } & Escena 4 & 7 \\
\cline { 2 - 3 } & Escena 5 & 6 \\
\cline { 2 - 3 } & Escena 6 & 24 \\
\cline { 2 - 3 } & Escena 7 & 27,28 \\
\cline { 2 - 3 } & Escena 8 & 3 \\
\hline \multirow{5}{*}{ Epílogo } & & Ninguno (Posible referencia a Caronte, obra de \\
& & Luciano) \\
\hline
\end{tabular}

El escenario es caracterizado por medio de una única acotación escénica inicial (Consolin Dezotti, 2003: 6). La escenificación del espacio dramático recurre a cuatro elementos característicos del Hades: el río que los muertos deben cruzar y que separa una zona desértica del Hades, el barco que conduce Caronte, Cerbero, el perro guardián de la entrada al Hades, y un árbol de granada, la fruta que el dios Hades le ofreció a Perséfone para forzar su matrimonio (cf. Himno homérico a Deméter, 370-383). Si bien no se encuentran otras acotaciones escénicas, por medio de los diálogos se infiere que el río debería desaparecer a partir de la escena 3 de la segunda parte y que en la escena 4 debería haber un lago. Quizás el epílogo, protagonizado por Hermes y Caronte, deba ser representado junto al barco y al río pues ese último personaje jamás abandonaba esa zona.

En relación con los personajes, su cantidad es menor pues varios diálogos han sido dejados de lado. Además, en los casos en los que es posible, algunos personajes han sido reemplazados por otros que, por lo tanto, han aumentado su participación en la obra. En la escena 2 de la primera parte, el pasaje basado en el diálogo 18 utiliza a Cenofante en lugar de Damnipo. Luego, en la misma escena, el pasaje basado en el diálogo 19, pone las palabras de Símilo en boca de Calidémides. Por último, en las escenas 5 y 7 , basadas respectivamente 
en los diálogos 6 y 27, Minos reemplaza a Éaco, pues ambos eran parte del tribunal del Hades.

Richard Walton, al referirse a los problemas de la traducción de piezas teatrales antiguas, sintetiza las condiciones que una buena traducción debe cumplir: traducir no es sólo la transmisión de un lenguaje a otro sino también la transferencia de un contexto y la búsqueda de balance en las referencias con la finalidad de ser fieles al original y, al mismo tiempo, posibilitar puestas en escena creativas. No se trata de traducir "arco" por "rifle" sino de encontrar un lenguaje que le permita al director crear un mundo escénico donde tanto los arcos como los rifles puedan parecer apropiados (2008: 155). Es decir, la traducción debe lograr una cierta universalidad que permita al espectador establecer una analogía entre su mundo y el mundo antiguo. En el caso particular de esta adaptación, la traducción evita este problema pues, aunque recurre a personajes mitológicos e históricos, la comicidad no se encuentra en la erudición sino en la crítica de tipos y de costumbres fácilmente reconocibles por el espectador. Además, el lenguaje coloquial griego ha sido adaptado a la lengua portuguesa hablada en Brasil. De esta manera, se garantiza que el espectador tenga una experiencia teatral que supere la brecha temporal que se extiende desde la escritura de este texto en el siglo II d.C. hasta su lectura o su escenificación en la contemporaneidad. 


\section{Bibliografía}

\section{Fuentes}

Luciano, Diálogos dos mortos, Trad.y adapt. de Maria Celeste Consolin Dezotti, Araraquara, Faculdade de Ciências e Letras - UNESP, 2003.

Macleod, Matthew (ed.), Luciani opera. t. IV, Nueva York, Oxford University Press, 1987.

\section{Bibliografía Crítica}

Cabrero, María del Carmen. “¡Arriba el telón! Discurso, identidad e ideología en tres diálogos de Luciano”, Nova Tellus 25,2, 2007, 209-230.

González Juliá, Lluís, “Luciano ensaya la novela escénica: apariencia episódica y estructura unitaria de los Diálogos de los muertos", en: Brandão, Jacyntho Lins (ed.), Actas del V Colóquio Internacional do Grupo Interdisciplinar de Pesquisas sobre as Sociedades Antigas (GIPSA) "Luciano e a tradição luciânica”, Ouro Preto, Brasil, 2009. [En prensa]

Mestre, Francesca, “Retórica y Diálogo contra el Sirio”, Synthesis 4, 1997, 21-31.

Mestre, Francesca y Pilar Gómez, "Retórica, comedia, diálogo. La fusión de géneros en la literatura griega del s. II d.C.”, Myrtia 16, 2001, 111-122.

Lanaud, Michaël, Le monde des morts selon Lucien de Samosate: une recréation originale du thème de l'Hadès au IIe siècle, Mémoire de Master 1 Poétique et histoire littéraire. Université de Pau et des Pays de l'Adour, 2010. [Fecha de consulta: 12/06/2011] Disponible en: http://dumas.ccsd.cnrs. fr/docs/00/49/04/61/PDF/2008-2009_Michael_Lanaud_master_1. $\mathrm{pdf}$

Walton, J. Michael, “Enough give in it': translating the classical play”, en: Hardwick, Lorna y Christopher Stray (eds.) A companion to classical receptions, Oxford, Blackwell Publishing, 2008, pp. 153-167.

Wiater, Nicolas, "Tragedies to laugh at - Lucian on the failures of mimesis", en: Mosaïque, $\mathrm{n}^{\circ} 1$, junio 2009. 